\title{
Invasion of Paddy Combine Harvester (PCH) and Its Socioeconomic Impacts: A Study based on Ampara District, Sri Lanka
}

\author{
Seeni Mohamed Ayoob \\ Head/ Department of Sociology, \\ Senior Lecturer Gr.I in Sociology, \\ Faculty of Arts and Culture, \\ South Eastern University of Sri Lanka \\ Mohamed Anifa Mohamed Fowsar \\ Senior Lecturer Gr. II in Political Science, \\ Department of Political Science, \\ Faculty of Arts and Culture, \\ South Eastern University of Sri Lanka
}

DOI: https://doi.org/10.36941/ajis-2020-0092

\begin{abstract}
The term mechanisation of paddy agriculture denotes that mechanical power is used in agriculture instead of human and animal power, which is totally diminished today. Paddy agriculture plays an important role in the Sri Lankan economy where rice is the staple food of the country. Ampara district in Eastern Province of Sri Lanka contributes to the national food production by through paddy cultivation. In Ampara district, the tractor was used in paddy agriculture that required the need for human power previously. Nevertheless, the invasion of Paddy Combine Harvester (PCH) has demolished the tasks done by human power in the paddy agricultural sector now. Harvesting, threshing and cleaning were carried out in different stages of a long period with multiple groups of people by using human power in the past. Now it has changed, and Paddy combine Harvester (PCH) is used for all works of harvesting, threshing and cleaning within a short period at present. This study was conducted to emphasise the changes caused by the mechanisation in paddy agriculture and examine the changes among the Muslim society after the invasion of Paddy Combine Harvester (PCH) in the paddy agricultural sector. The decline in collective action and social solidarity among family members and society, loss of farming-related celebrations and ceremonies, the decline of the contribution of women in the agriculture and loss of job opportunities and income were found to be the negative impacts of the invasion of the paddy combine harvester. The decline in the disparities among landlords and peasants, changes in the food and dressing pattern, new employment opportunities and income generation, changes in the education sector, speedy harvesting in the rainy seasons and reduction in workload and less time consumption were found to be the positive impacts of the invasion of paddy combine harvester (PCH).
\end{abstract}

Keywords: Mechanisation, Paddy Combine Harvester, Poverty, Social disorganisation

\section{Introduction}

Agriculture is the base of every society in the world. People have started their communal living with the introduction of agriculture and farming. Paddy cultivation has a long history along with human 
evaluation. Agriculture plays a vital role in the Sri Lankan economy where more than half of the populations rely on the agricultural sector in Sri Lanka. Paddy cultivation is given utmost importance in the agriculture industry where rice is the staple food of Sri Lanka.

The history of paddy cultivation in Sri Lanka traces its roots back to between $161 \mathrm{BC}$ and 543 B.C. (Ahamed Lebbe, 2010). The appropriate climatic condition of the island Sri Lanka helped to rely on paddy agriculture since past. The kings and other rulers have supported and implemented several massive irrigation plans in Sri Lanka with the understanding of its significance in the societal and economic wellbeing of the people and country. People had and still having high expectation and trust in paddy agriculture, which make paddy cultivation as their way of life.

The involvements of the workforce and labour force have been very high in paddy agriculture from the past. Most of the rural villagers have been relying on paddy cultivation and its related works in Sri Lanka. However, this condition has been changed due to the mechanisation and new technological invasion in paddy agriculture in Sri Lanka. At present, much of the human and animal labour is replaced with mechanisation with adherent technology that adds a greater deal of efficiency towards the production process.

The process of mechanisation refers to the application of machines or mechanised power for the production of goods, which have economic values (Rao, 2003). Bhattacharjee also highlighted that the application of machines power to work on the land, usually performed by bullocks, horses and other drought animals or by human labour is characterised by the mechanisation of agriculture and farming process. Numerous machines are commonly used in the agricultural sector and paddy cultivation. These machines are used from the initial stage like levelling the lands and the final stage of harvesting in the paddy cultivation.

Paddy agriculture is being divided into three periods related to the usage of machinery in Eastern Sri Lanka. The human labour force and animal power were highly used in the first period before the 1950s. The invasion of machinery has started to increase in the second period after the 1950 s in paddy agriculture (Victor, 1997). This second period is a mixed up with the involvement of the human workforce and machinery in paddy agriculture. The paddy lands were prepared with the use of tractors, and human hands reaped the paddy cultivations and gathered in one place in a bundle. The paddies were threshed, and rice was removed with the use of both machines and human power. Finally, rice seeds were packed in sacks and sent to the landowners' house in tractors. The usage of tractors is high in this period.

The introduction of new machinery in paddy agriculture in the post-war period has created the third stage in paddy agriculture. The usage of the paddy combine harvester in paddy agriculture has increased in the study area recently. A combine paddy harvester is a machine that combines three tasks such as harvesting, threshing and cleaning grain crops. The need for the human labour force and animal power has begun to decline rapidly in the paddy agricultural sector after the introduction of the paddy combine harvester. The need for human labour is significant in the second period of paddy agriculture, where human labour force worked together with the tractors and machines. However, after the invasion of the paddy combine harvester, the need for human labour force has reduced dramatically.

\section{Research Objective}

This study was conducted to emphasise the changes caused by the mechanisation in paddy agriculture and examine the changes among the Muslim society after the invasion of Paddy Combine Harvester $(\mathrm{PCH})$ in the paddy agricultural sector.

\section{Literature Review}

Balasooriya (2017) highlighted that contributing to about $08 \%$ of the GDP; agriculture sector plays a pivotal role in Sri Lanka. The variety of machinery was required for the agricultural sector, which 
varies from small hand-held tools or equipment to large scale engine-driven machines. Agricultural mechanisation policy and agricultural policies were initiated in Sri Lanka to incorporate machinery in agriculture to increase output in the agricultural sector. The technological institute was established in some important parts of the country. He also pointed out that the level of mechanisation is high in paddy cultivation where nearly $95 \%$ of land preparation is now mechanised compared to vegetable cultivation, other field crops, fruit sector plantation crops and spices.

Lasantha Wickremesooriya (2015) elaborated in his essay on Farm Mechanization: Accelerating the Country's Food Security drive that mechanisation has infused in the country slowly in the industry in Sri Lanka and at the beginning, it was used only for large scale plantation in 1952. He noted that today more and more farmers are adopting the use of tractors for their agricultural activities. He noted that various machines are used in agriculture. The advantages of mechanisation have been found to be improved by speedy completion of tasks, improved soil management, improved water management, better use of land management, significantly reducing herbicide use, increasing yields and better post-harvest management.

Ayoob (2013) carried out research on Technological Advancement and its Impact on the Traditional Way of Life in the Rural Farming Society: South Eastern Region of Sri Lanka. This study illustrated the implications of technological advancements used in agriculture in rural farming society. The study found that technological advancement helps the poor farming community to get an education and change their lifestyle. The detrimental impacts of these technological advances have also been recognised as unemployment, the loss of social customs traditionally celebrated during the harvest, and the loss of collecting spilled paddy in the harvesting season.

Pathirana, Bandara, Ratnaweera, Balasooriya, Bandara, conducted research on Sustainable Farming through Mechanisation: Development of a Bund Making machine in 2010. They have pointed out that to motivate the young people in to agriculture, mechanisation plays a vital role. They described mechanisation in bund making process in low land paddy fields. The study concluded that roughly about 30-fold productivity gain in terms of timing consumption is expected with the introduction of this mechanisation compared to the conventional methods currently used by the farmers.

\section{Research Methodology}

\subsection{Study area}

Amparai district of Sri Lanka is selected for the current research study. It should be noted that Amparai district has in all 20 Divisional Secretariats, of which o8 Divisional Secretariat areas were selected for the study. They are Irakkamam, Sainthamaruthu, Ninthavur, Addalaichenai, Sammanthurai, Kalmunai, Akkaraipattu and Pottuvil. Ampara district entail of 444,539.10 hectares of the land extent and populated land extent is 154 square kilometres. Ampara District is one of the paddy growing districts in Sri Lanka, which makes up the most significant share of paddy production in Sri Lanka. The majority of the people in Ampara district are engaged in paddy cultivation as their livelihood, contributing more than $20 \%$ to the national economy through rice production. Even though available paddy cultivation extent in Ampara is about 94,180 Ha, normally 88,100 and 68,300 Ha of paddy land will be cultivated during Maha and Yala respectively including major, minor, and rain-fed areas in the Ampara district (Annual Performance Report and Accounts, District Secretariat, Ampara, 2018). $45 \%$ of the people directly engaged in paddy cultivation and related activities and $35 \%$ of the people indirectly engaged in paddy cultivation and related activities in Ampara district (Ahamed Lebbe, 2010).

\subsection{Data collection and data analysis}

The study was conducted by using both primary and secondary data collection methods. The primary 
data was collected from the interview, focused group discussion and observation. Fifty interviews and o2 focus group discussion were carried out in order to get sufficient information to the study. Annual Performance Report and Accounts, District Secretariat, Ampara, 2018, books, journal articles, newspaper articles, online archives and other relevant documents were used as the secondary data. The results of the study were presented and discussed in qualitative descriptive methods.

\section{Results and Discussion}

The mechanisation of the paddy agriculture industry, particularly the invasion of Paddy Combine Harvester has brought many positive and negative impacts in the Muslim society.

5.1 Negative impacts of mechanisation in paddy agriculture after the introduction of the paddy combine harvester

\subsubsection{The decline in collective action and social solidarity among family members and society}

The people in the traditional agricultural society lived a meaningful life with cooperativeness and collectively. The whole members in the families of traditional agricultural society had a practice of engaging in the paddy fields in every period. The paddy lands and paddy fields were served as a base of integrating people in the society and agent of providing job opportunities to the people. The workloads in paddy agriculture were distributed among the people based on age and gender. Paddy agriculture was served as the focal point that helped the youngsters to practice agricultural-related works. This condition had made the people to not to hire people from other areas to their works in the paddy fields. They got high profit too. Solidarity, mutual understanding, responsibility, collective actions and working group mentality were highly developed among the family members in the previous agricultural societies.

The introduction of machines has destroyed this connection and bonds among the members of the family and has made the people into different individuals. Every activity in paddy agriculture has been carried out by using machines, which has created a situation of not dependent on human beings. The total family members who worked in the same paddy fields before have been moved to seek other job opportunities in the outer areas because of this mechanisation of paddy agriculture. This condition has diminished the group spirituality and social solidarity among the family members in the society. The situations of family get-together also washed out from the people. The tradition of working together and collective actions in the paddy fields is evacuated from the society, and it is not seen further.

Social solidarity connects every individual in society and creates ways to make collective actions among the people. The living standard and life of the people have become enhanced through these collective actions. The different stages and activities in paddy agriculture have paved the ways to create collective actions among the people that lead to the improvement of the individuals and society. The collective actions in traditional agriculture started from the discussion of the date of sowing and ended with the harvest of the paddy fields. The neighbours of the paddy fields also shared their food items with other neighbours. The people also provided their support to others with collective feeling. The owners of the paddy fields also hired peasants to work with them in their paddy lands, which created opportunities among the high class and low-class people to work together in the same paddy fields.

The ancient periods that were used human labour force are the periods where the relationships among the societal members became stronger and social solidarity was firmed. The introduction of the paddy combine harvester with new modern technology in the paddy agricultural sector reduced the workload of the human labour force that is resulted in the reduction of social solidarity and collective action among the people. 


\subsubsection{The loss of farming-related celebrations and ceremonies}

The celebrations and ceremonies hold the people together with happiness, and it also a very thoughtful way to overcome the sorrows in our life. The celebrations are everywhere, and all the people become enthusiastic and energetic during the festival period. The traditional agricultural society people in the previous era has celebrated a number of events and ceremonies related to farming and paddy cultivation in order to express their happiness as well as gratitude to the God, people, birds and other animals who supported them in numerous ways.

Since the beginning of the paddy cultivation, people started to work together, they would like to offer special food items to the people working on field fields, and they considered it as small festivals among them to cheer up the hard-working farmers. For instance, people provided breakfast to the workers in the paddy field on the previous day of sowing. They often made rice roti and stratified it in a desk in the paddy field areas. This roti helped the workers to overcome their hunger. The family members formed some temporary hopper hut and provided hoppers and sweet food with fresh milk. They distributed this food to other neighbour paddy fields' workers and passers-by too. People cooked lunch for the workers in the harvesting time too. They cook white rice with cassava, pumpkin and meat. This food is often eaten by the people using areca leaf.

In the threshing period, the children and grandchildren of the paddy landowners often visited in the bullock cart to the paddy fields and enjoyed their time there with full of happiness. The children haunted small fishes in the canals too. After harvesting, poor people visited the site and asked for oblations. The farmers offered paddies to these people; even poor farmers also wished to provide whatever they have harvested. This help made the poor beggars with happiness. After finishing every work related to paddy agriculture, the village people got together and prepared a special lunch called Kanthoori. People of the area often participated in this event without any racial and ethnic differences.

It would become a massive celebration in the traditional agricultural society. However, this sort of festivals and ceremonies are diminished in society due to the mechanisation of paddy agriculture, and the introduction of paddy combine harvesters in paddy agriculture. Most of the people forget about these customs of having festivals and sharing their joys with others and expressing their gratitude to the respective people.

\subsubsection{The decline of the contribution of women in agriculture}

The contribution of women in agricultural activities is immeasurable from the past. It was unavoidable neediness felt by everyone in society. Women gave their support in paddy agriculture similar to men in the ancient agricultural societies. Men and women in the agricultural society worked together, which is similar to how the men and women in modern society work together now. Weeding, helping the farmers in needed ways, giving bags and boxes while threshing, helping the farmers to separate paddy and chaff, etc. are some major works carried out by women in the paddy agricultural sector. They received extra bags of paddy along with their wages. The wife of the paddy landowners and other family female members had the custom of helping in numerous ways in agriculture. Women cooked food items for the husband, and she delivered mostly the food personally. She prepared black tea and snakes for her family members working in the field too. In the threshing days and harvesting period, women prepared food items to all, and they helped in soaking the seeds too.

The work of the women labours in paddy agriculture is another source of income to the family members. These earnings of women were not only supporting the financial burden of the family and the husband but also it strengthened the relationship between husband and wife in the traditional agricultural society. However, the usage of the paddy combine harvester and new farming technologies put a break to the women participation and make them to be at home. Mechanisation separates husband and wife, and their cooperate earnings in agriculture. 


\subsubsection{Loss of job opportunities and income}

The mechanisation of paddy agriculture with the introduction of paddy combine harvester has also created situation joblessness and lack of income among the labourers in the farming sector. The poor wage labours forcefully abandoned their works that are retaken by paddy combine harvester today. Previously, the poor wage labourers who were fully dependent on paddy agriculture did a number of works in the fields. They did land preparation, ploughing, cleaning, constructing field bunds, cleaning canals, levelling the lands manually, sowing, diverting water to the lands, applying fertiliser, spraying pesticides and weedicides, weeding, planting, fencing, harvesting and threshing.

Nowadays everything has been changed, and people lost their wages and involvement in paddy agriculture because of mechanisation. These new technologies and machinery, such as paddy combine harvester and tractors in the agricultural sector, chased most of the labourers in farming. Most of them are remaining at homes and street without any job opportunities, which they have known and done before. This situation induced the existing poverty into the worst condition among the people.

Collecting spilled ears at the paddy field is an additional income of the poor people during the harvesting season. But, after the invasion of Paddy Combine Harvester, this traditional spilled ears collection system is also given up by the people. Paddy Combine Harvester collects the ears without spilling on the paddy field. So, the uses of new Paddy Combine Harvester have directly affected the economic activities of the poor people in society. (Ayoob, 2013)

5.2 Positive impacts of mechanisation in paddy agriculture after the introduction of the paddy combine harvester

The mechanisation of paddy agriculture after the introduction paddy combine harvester has brought many positive changes not only in the farming and agricultural sector but also in the agricultural societies too.

\subsubsection{The decline in the disparities among landlords and peasants}

The society has changed into a new form, which resulted in diminishing inequalities among the people. Disparities among the landlords and peasants were highly visible in the previous paddy agricultural societies. Landlords had high control over the peasants, and their relationships are not that much flexible. The peasants had considerable restrictions in their relationship related to traditional agriculture. This kind of relationship is diminishing in modern society because of mechanisation and new technological innovations. The landlords have started to use machines instead of human labour-power, which has helped to let down the superiority of the landowners over the wage labourers. This is one of the positive impacts of mechanisation of paddy agriculture after the introduction of the paddy combine harvester.

\subsubsection{Changes in the food and dressing pattern}

The mechanisation in paddy agriculture has brought changes in the food and dressing pattern of the people in agricultural societies. Previously people of paddy agriculture mostly ate yams and porridge for breakfast and worked in the paddy fields. They ate rice three times. Now the food culture of people was changed along with the modernisation, and people started to eat varieties of food items that contain needed nutrition.

The dressing patterns of the people have also changed along with the passage of time. The men among the peasants in the paddy agricultural societies wore 'sarams' (a type of dress worn by men), and women wore half sarees a type of dress worn by women) previously. Through their dressing pattern, it could be easily identified who were landowners and labourers people in traditional 
societies. Now, this dressing of the people has altered with new modern dresses that have brought an equal status to everyone.

\subsubsection{New employment opportunities and income generation}

The labourers who lost their jobs due to the mechanisation and technological innovations like paddy combine harvester have found out new employment opportunities. Most of the men among the peasants have migrated to foreign countries for earnings and engaged in business. These new jobs have brought changes in their life, and it brings good income to run their families too. Also, the relationship and contact with others also enhanced through these new jobs. People started to build new houses with enough facilities. The lifestyle of people also changed.

\subsubsection{Changes in the education sector}

Paddy cultivation and its related activities were the prime earnings of the people in the study area. The interest in education was very low among the people because of the thirst in paddy agriculture and the income from it. 'Intensive implementation of education in mother tongue' is one of the initiatives brought by the Sri Lankan government after the 1950s. This initiative in studying in mother tongue has made the people become more interest in learning. Along with the introduction of machinery in the agricultural sector, also reduce the need for manpower. These circumstances have made the farmers and labourers who already involved their children in the paddy cultural set up to focus on education (Victor, 1997).

There was a lack of employment opportunities found in the paddy agricultural sector because of the new machines and technological improvements. The machines like paddy combine harvester and tractors are used instead of the human labour force in every aspect of agricultural-related works. Therefore, people focus more on education and learning to find a job in the job market. The students who are not selected for the universities and higher education institutions also continue their education in private institutions by completing vocational courses. They find jobs in foreign countries and generate income to look after their families.

\subsubsection{Reduction in workload and less time consumption}

In the past, many paddy-related works were done with the help of human resources, and it took a great deal of time and money. The advent of new machinery in agricultural operations has reduced the cost and time of the farmers (Ayoob, 2013). Since the beginning of the paddy cultivation to harvesting, it required a huge labour force and time. Approximately 20 labourers should work 5-6 days for at least 05 hours per day for each activates in the agricultural lands. Particular groups of people did most of these activities where it was found to be challenging to get the labour from these groups in the appropriate periods. The maintenance also became difficult at that time. However, this problem has been overcome after the introduction of the paddy combine harvester in modern paddy agriculture.

The time consumption and extensive labour work in the agricultural sector required more days in the traditional agricultural sector. People often suffered in the rainy season because of the lack of requirements to speed up their harvesting before it vanished in the rain. It was found to be very difficult to do harvesting in the rainy season. Mostly the paddy fields were destructed heavily in the rainy seasons, and poor farmers were suffered from poor outcome and loans related to it. Therefore, the introduction of machines and new equipment has helped to overcome these issues of the rainy season.

\section{Conclusion}

People have started their communal living with the introduction of agriculture and farming. Agriculture plays a vital role in the Sri Lankan economy where more than half of the populations rely 
on the agricultural sector in Sri Lanka. Most of the rural villagers have been relying on paddy cultivation and its related works in Sri Lanka. However, this condition has been changed due to the mechanisation and new technological invasion in paddy agriculture in Sri Lanka. At present, much of the human and animal labour is replaced with mechanisation with adherent technology that adds a greater deal of efficiency towards the production process. This study focused on the changes in paddy agriculture commonly. It examined the changes among the Muslim rural society after the invasion of paddy Combine Harvester ( $\mathrm{PCH})$ in the paddy agricultural sector.

The decline in collective action and social solidarity among family members and society, loss of farming-related celebrations and ceremonies, the decline of the contribution of women in the agriculture and loss of job opportunities and income were found to be the negative impacts of the mechanisation and the invasion of the paddy combine harvester. The decline in the disparities among landlords and peasants, changes in the food and dressing pattern, new employment opportunities and income generation, changes in the education sector, speedy harvesting in the rainy seasons and reduction in workload and less time consumption were found to be the positive impacts of mechanisation and the invasion of the paddy combine harvester. Mechanisation has become an unavoidable factor in society today. It is impossible to put barriers and stop the mechanisation and technological advancement in the agricultural sector. However, it is highly possible to reduce the negative impacts bring up by the mechanisation in the agricultural sector.

\section{Recommendations}

The influence of technology has evolved in every aspect of people's life. Mechanisation has become an unavoidable factor in society today. It is impossible to put barriers and stop the mechanisation and technological advancement in the agricultural sector. However, it is highly possible to reduce the negative impacts bring up by the mechanisation in the agricultural sector. The capitalists get more profit because of the machines; on the other hand, the poor labourers are severely affected through this mechanisation in the agricultural sector. The poor wage labourers who earned money by engaging in numerous works such as land preparation, ploughing, cleaning, constructing field bunds, cleaning canals, levelling the lands manually, sowing, diverting water to the lands, applying fertiliser, spraying pesticides and weedicides, weeding, planting, fencing, harvesting and threshing in the paddy agriculture lost their works and income today. Therefore, identifying relevant jobs to these poor wage labourers in other sectors and guiding them to continue their life without income barriers.

The contribution of women in the agricultural sector was significant, but the mechanisation has reduced the chance of women workers in the paddy agriculture. There were two kinds of women worked in the paddy lands as wage labourers and the family members of the landowners. They have lost their income and contribution to agriculture. Therefore, providing suitable self-employment opportunities to these women is crucial to obtain the income again, which they have lost in paddy agriculture. Providing sewing machines, mat weaving and making mixtures are some examples of self-employments. The poor waged labourers who worked in the paddy lands previously are going abroad to find the source of income. However, they are going without proper training and knowledge that leads them to get low pay. Therefore, providing training related to the jobs and make them into skilled labourers are essential to get high income.

The machines are highly used in ploughing the field and harvesting. It is suitable to give working opportunities to the local wage labourers to do the other labour works like cleaning, constructing field bunds, cleaning canals, sowing, diverting water to the lands, applying fertiliser, spraying pesticides and weedicides, weeding, planting and fencing. Therefore, the agricultural-related organisations should take initiatives to confirm about it. Making the school students aware of the importance of traditional agriculture, cultural influences and group solidarity through dramas, short films, and folksongs are essential to transmit the traditional views among the new generation. The agricultural-related works and involvement in paddy agriculture are viewed as a disrespectable work in modern society. The younger generations are not willing to do so. There are people still exist in the 
society which specifically learnt about agriculture. Therefore, the involvement of such knowledgeable and experienced people in the paddy agriculture would definitely earn respect and huge profit.

Ampara district is a coastal area with a long beach and aquatic resources. It also comprises the South Eastern University of Sri Lanka that has included courses related to the fishing industry. Therefore, providing fishing equipment with the help of government and non-government institutions and job-related training and facilitation to the labourers from the university system are vital ideas to the jobless people due to the mechanisation in paddy agriculture. The government should provide loan and leasing facilities to the poor farmers and as well as the Non-government organisations should give equipment by making them into small groups. Taking initiatives to provide water facilities to the water scarcity paddy fields is also helpful to reduce joblessness in the paddy agricultural sector.

\section{References}

Aditya, H. (n.d). Mechanisation of agriculture: meaning, benefits and progress. Retrieved from http://www.economicsdiscussion.net/india/farming/mechanization-of-agriculture-meaning-benefits-andprogress/21655 [accessed on Mar 06 2020].

Ahamed Lebbe, S.M. (2010). Trend of paddy sector in Ampara district. International Journal of Kalam, 5(1), 6-15.

Ayoob, S.M. (2013). Technological advancement and its impact on the traditional way of life in the rural farming society. Retrieved from http://ir.lib.seu.ac.lk/handle/123456789/271

Balasooriya, B.M.C.P. (2017). Agricultural mechanization: Status, challenges and opportunities in Sri Lanka. In Gurung, T.R., Kabir, W., \& Bokhtiar, S.M. (Eds.), Mechanisation for sustainable agricultural intensification in SAARC region (pp. 229-248). Dhaka, Bangladesh: SAARC Agriculture Centre.

District Secretariat. (2018). Annual performance report E accounts-2018. Ampara, Sri Lanka: District Secretariat.

Giddens, A. (2005). Sociology. Cambridge: Polity Press.

Haralambos, M., \& Martin Holborn, M. (2004). Sociology: Themes and perspectives. London: Harper Collins Publishers Limited.

Pathirana, P.H.S, Bandara P.C., Ratnaweera, A.C., Balasooriya, C.P., Bandara M.A. (2013). Sustainable farming through mechanisation: Development of a bund making machine. Retrieved from http://www2.civil.mrt.ac.lk/conference/ICSBE_2010/vol_02/65.pdf

Rao, C.N.S. (2003). Sociology: Primary principles. New Delhi: S.Chand and Commpany Ltd.

Victor. (1997). Muslim nation and its future. Akkaraipattu: Moontravathu manithan Publication.

Wickremesooriya, L. (2015). Farm mechanisation: Accelerating the country's food security drive. Retrieved from http://www.ft.lk/article/485819/Farm-mechanisation--Accelerating-the-country-s-food-security-drive 